\title{
Enhancement of the Photodegradative Potential of Polymer Composites Containing Babassu Fiber
}

\author{
Josélia Borges de Moura Furtado ${ }^{a}$ (D), Paulo Afonso Furtado Filho ${ }^{b}$, Thalyta Pereira Oliveira ${ }^{a}$, \\ Marlo Rodrigues de Sousa Caetano ${ }^{a}$, Inês Maria de Souza Araujo ${ }^{a}$, Francisco Cardoso Figueiredoc, \\ José Ribeiro dos Santos Júnior ${ }^{a}$ \\ ${ }^{a}$ Universidade Federal do Piaui, Departamento de Química,Teresina, PI, Brasil \\ ${ }^{b}$ Universidade Federal do Piauí, Centro de Educação Aberta e a Distância - CEAD, Departamento de \\ Física, Teresina, PI, Brasil \\ ${ }^{c}$ Universidade Federal do Piauí, Escola Técnica de Teresina, Teresina, PI, Brasil
}

Received: July 24, 2019; Revised: March 02, 2020; Accepted: March 27, 2020

\begin{abstract}
Vegetable fibers are widely used as reinforcement in the production of composites. In this work, the photodegradative potential of polymer composites containing babassu fiber was characterized and evaluated. The fibers were extracted manually and immersed in a $10 \% \mathrm{NaOH}$ solution (Mercerization). After drying, they were crushed and incorporated into the low-density polyethylene matrix in proportions of $5 \%, 10 \%$, and $20 \%$ of the total mass of the composite. The composites were subjected to Scanning Electron Microscopy analysis (showed the incorporation of fibers into the polymeric matrix), Infrared Spectroscopy (the presence of fiber was observed with peaks at 3200-3600 $\mathrm{cm}^{-1}$, and $1596 \mathrm{~cm}^{-1}-1036 \mathrm{~cm}^{-1}$ ), Mechanical Tests (with 20\% fiber, there is a 44\% decrease in tension, $48 \%$ in strain and $12 \%$ in Young's modulus) and Thermogravimetric Analysis (inicial fiber degradation starts between $220-337^{\circ} \mathrm{C}$, and matrix degradation between $333-550{ }^{\circ} \mathrm{C}$ ). The composites were subjected to degradation processes by solar radiation and under artificial UV-B. Samples of oxy-biodegradable plastic bags were also degraded under the same degradation conditions of the composites. These results show that the materials used in the research, besides presenting an excellent degree of compatibilization, also reveal an improvement in the photodegradation potential of composites.
\end{abstract}

Keywords: Composites, mercerization, natural and artificial degradation.

\section{Introduction}

Vegetable fibers are composed of cellulose, hemicellulose, lignin, pectin, wax and other compounds soluble in water ${ }^{1,2}$. Lignin is an aromatic biopolymer present in cell walls of all plants and hemicellulose is constituted by a group of low molecular mass polysaccharides that typically occur in association with cellulose and lignin ${ }^{2,3}$. The cellulose compound in a larger amount is a linear homopolymer composed of glucose units that are joined through glycosidic linkages of the type $\beta-(1,4)$, or between the carbons $\mathrm{C} 1$ and $\mathrm{C} 4$ of $\beta$-D- glucopiranose ${ }^{4}$.

The vegetables fibers are commonly used in the production of polymer composites as they have great advantages such as good availability, low molecular weight, biodegradable, low cost, good thermal and mechanical properties, renewable, recyclable, may be incinerated, can be easily modified by chemical agents, non-toxic, etc. As disadvantages, the fibers absorb moisture, vary in quality, and have low compatibility when united in polymer matrix hydrophobic $\mathrm{c}^{2,4-14}$. The hydrophilic nature makes it inherently incompatible with thermoplastic hydrophobic polymers, such as polyethylene of high and low density, due to its high molecular weight and its long-chain

*e-mail:joseliafurtado@gmail.com. inert vegetable fibers ${ }^{15}$. A possible solution for better interfacial interaction of the fiber with a non-polar polymer matrix is to make use of surface chemical treatments, which physically and chemically modify the fiber. There are several types of treatment including acetylation, etherification, peroxide treatment, mercerization ${ }^{9,13,15}$, etc.

Over the years, researchers have been studying various fiber treatment methods in order to obtain high-quality fibers with good compatibility when applied in the production of composites. Huzaifah et al. ${ }^{13}$ reviewed previous work on the use of natural fibers in the production of polymeric composites, and Kocsis et al. ${ }^{11}$ summarizes the recent (from year 2000) advancements in the interphase tailoring of fiber-reinforced polymer composites.

The mercerization was chosen in this work because it is a simple and efficient method for the production of high-quality fibers. The mercerization process consists of treating the natural fiber surface with a solution of concentrated sodium hydroxide, producing enough to reduce the linear density and the swollen fiber shrinkage, revealing the fibrils, and allowing the emergence of a rugged topography which also increases the number of possible reactive sites, enhancing and increasing the interfacial adhesion compatibility of the natural fiber with a polymer matrix ${ }^{15}$. The mercerization 
also has an effect on the chemical composition of the fiber, the degree of polymerization, and the cellulose crystallites molecular orientation, due to the lignin and hemicellulose removal during the process $s^{4,13,16,17,18}$.

There are several studies in the literature that make use of mercerization as a surface fibers treatment. For example, El-Shekeil et al. ${ }^{16}$ used this method for polyurethane matrix compatibility with kenaf fiber. Barreto et al. ${ }^{2}$ used mercerization to form biocomposites based on cardanol, while Kim and Netravali ${ }^{19}$ studied the effects of the mechanical properties in reinforced composites with sisal fibers. Ilyas et al. ${ }^{15}$ studied the effects of delignification and mercerization on the physicochemical and thermal properties of sugar palm fiber. Its characteristics were examined for the preparation of a hydrolysis treatment to produce nanocrystalline cellulose for the reinforcement of polymer composites. Ashori et al. ${ }^{17}$ made a study of the chemical treatment on the cellulosic surface active sites, and Qin et al. ${ }^{4}$ studied the properties of the composite containing cellulose. Huzaifah et al. ${ }^{13}$, reviewed the natural fibers with a greater focus on sugar palm tree fibers, including the background of the tree, the properties of its fiber, and the treatment to increase the compatibility between matrix and fibers. Bachtiar et al. ${ }^{20}$ studied the effect of the alkaline treatment technique, to modify sugar palm fiber surface, on the tensile and impact properties of sugar palm fiber/epoxy composites. Wang et al. ${ }^{5}$ examined the effect of treatment on the composites mechanical properties reinforced with polypropylene and fiber jute, while Kalia et al. ${ }^{8}$ used mercerization in the natural fibers treatment and its applications in reinforcing polymeric materials. Ilyas et al. ${ }^{14}$ have studied different stages of treatment on the polysaccharides (hemicelluloses and cellulose) and lignin of sugar palm fibers (bleaching, alkali treatments and hydrolysis), and Ilyas et al. ${ }^{21}$ have also studied isolated nanofibrillated cellulose from sugar palm fibers through chemo-mechanical treatments, by using high pressurized homogenization, assisted with delignification, mercerization, and refining pre-treatments.

The use of fibers in a polymer matrix has gained much attention due to the "environmentally friendly" features presented by these materials. The presence of used plastic bags in the environment is the subject of concern, not only in scientific circles, but also in society. These materials contribute to an increased volume of solid waste in the environment. Polyolefins are responsible for this increase, especially polyethylene, since many industrially produced materials make use of these materials. An alternative, in addition to recycling, is the use of natural fibers embedded in thermoplastic matrices ${ }^{11,22}$. The composites with these types of materials have great advantages such as high efficiency, and a higher rate of degradability. Concern for the environment is one of the global ${ }^{11,13}$ issues today.

It is very important to highlight here that in the literature, there are no studies related to the production of polymer composites using babassu palm stem fiber as a reinforcement in low-density polyethylene matrix, and their subsequent application in the improvement in the photodegradative potential. Babassu fiber is highly abundant in Brazil and the mercerization is an efficient superficial chemical treatment method. In this study, low density polyethylene (LDPE) was used as a polymer matrix for the formation of composites with fibers from the babassu palm stem, treated with mercerization. The treated fibers were used to construct the composite mass in different proportions of fiber: $5 \%, 10 \%$, and $20 \%$. The degradation study of these new materials in natural conditions (solar radiation), and artificial conditions (UV-B) was carried out for comparison of the two procedures in commercial oxy-biodegradable plastics, which are plastics that are obtained from conventional polyethylene.

\section{Materials and Methods}

\subsection{Materials}

Babassu fibers were extracted from a palm tree (Attalea speciosa) located in the city of Teresina (Latitude: $5^{\circ} 5^{\prime} 21^{\prime}$ ' S, Longitude: $42^{\circ} 48^{\prime}$ 6" W) State of Piauí, Brazil. Low-Density Polyethylene (LDPE) in granule form was provided by the Camaçari Petrochemical Complex - Bahia, Brazil PLASTNOR S/A. The reagent used for mercerization was sodium hydroxide ( $\mathrm{NaOH}$ 99,9\%) supplied by Sigma Aldrich. SISGen code ABB8AA8.

\subsection{Methods}

\subsubsection{Mercerization of fibers}

The chemical treatment process of the fibers (mercerization) and the formation of the composite were performed at the Laboratory of Synthesis, Department of Physics, Federal University of Piauí-UFPI, Brazil. Initially, the fibers were removed from the stem of the babassu palm, then dried in an oven for 24 hours at $60{ }^{\circ} \mathrm{C}$ for a further crushing process. After crushing, the collected fibers were immersed in $10 \%$ $\mathrm{NaOH}$ solution at $80^{\circ} \mathrm{C}$ for 2 hours. Then, the mixture was filtered and the fibers were washed with distilled water to remove excess $\mathrm{NaOH}$ and impurities, until it reached neutral $\mathrm{pH}$. The fibers were dried in an oven at $60^{\circ} \mathrm{C}$ for 24 hours. Thereafter, the fibers were taken to a slicer which transforms the original fibers into milled and mercerized fibers, to obtain fibers with small sizes. In this way, mercerized babassu fibers were obtained for the preparation of the composites.

\subsubsection{Composite films}

For the preparation of composites, $0.30 \mathrm{~g}$ pure LDPE matrix was weighed. The fiber mass used in the composite preparation corresponded to a percentage of $5 \%, 10 \%$, and $20 \%$ by weight of pure matrix. Before the composite was formed, the material (LDPE and babassu fiber) underwent an agglomeration system that consisted of a sand bath heated to a temperature of $200^{\circ} \mathrm{C}$. By means of this system, it was possible to mix the materials so that the fibers were distributed in the polymeric matrix, allowing the production of high-quality composites. After the sand bath, the composite formation was carried out by means of a mechanical press, EMIGGIACCIO PHS $15 \mathrm{t}$, in which the materials were pressed at the temperature of $170{ }^{\circ} \mathrm{C}$, and pressure of 4 ton, for $15 \mathrm{~s}$. Through this procedure, the pure matrix and composite were obtained.

\subsubsection{Tensile testing}

For the production of composites, the ASTM D638 standard was used (Figure 1). $10 \mathrm{~g}$ of the ground babassu fiber blend 
and LDPE in different proportions (pure matrix and composites $5 \%, 10 \%$, and $20 \%$ fiber weight), were used. After obtaining the materials mixture, they were pressed, crushed and placed in the mold at the temperature of $180^{\circ} \mathrm{C}$, under a pressure of 1 ton, for a time of $15 \mathrm{~s}$. The composites were removed after the mold reached a temperature of $60^{\circ} \mathrm{C}$. The mechanical tests were performed using a universal test machine, Shimadzu Autograph AG-X $250 \mathrm{kN}$. All composites were tested at a speed of $5 \mathrm{~mm} / \mathrm{min}$. The tests were performed in duplicate.

\subsubsection{Infrared spectroscopy (FTIR)}

The formation of new absorption bands of the pure matrix and of the produced composites $(5 \%, 10 \%$, and $20 \%$ fiber weight), was measured by infrared spectroscopy. The samples were analyzed by ATR, in a BRUCKER brand, model VERTEX 70 , ATR, using OPUS software, in the region of $400-4000 \mathrm{~cm}^{-1}$ with a margin of error of $4 \mathrm{~cm}^{-1}$, and with a total of 64 scans for each sample (temperature $19^{\circ} \mathrm{C}$ and humidity below $50 \%$ ).

\subsubsection{Scanning Electron Microscopy (SEM)}

The morphology of the pure matrix and composites (5\%,10\%, and 20\% fiber weight ) was observed using scanning electron microscopy (SEM). The SEM images were made using a Shimadzu, model SSX-550 SuperScan. The samples were coated with a thin layer of gold (Metallizer Sanyu Electron, QuickCoater model SC-701). The acceleration voltage used was $15 \mathrm{Kv}\left(\mathrm{T}=20^{\circ} \mathrm{C}\right)$.

\subsubsection{Thermogravimetry (TG)}

The thermal degradation of the samples (pure matrix and composites 5\%,10\%, and 20\% fiber weight) was performed by thermogravimetry. The measurements were made on the TG/DTG-DTA Q600 TA Instruments module, in the temperature range between room temperature and $25-900{ }^{\circ} \mathrm{C}$, at a heating rate of $10^{\circ} \mathrm{C} / \mathrm{min}$. For the analyses, a mass of $10 \mathrm{mg}$ of the samples was used.

\subsubsection{Degradation in natural conditions (solar radiation)}

The degradation of pure polymeric matrix samples and composite containing $20 \%$ by weight of babassu fiber was

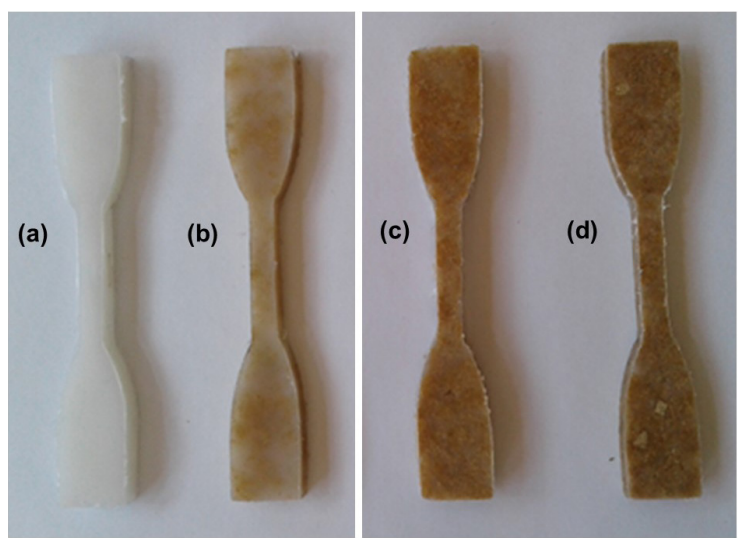

Figure 1. Composites containing babassu fiber and low-density polyethylene (a) LDPE 100\% (b) LDPE 95\% (c) LDPE 90\% and (d) LDPE $80 \%$. carried out in a natural environment. The samples were exposed under solar radiation in an open area for 768 hours. The samples were degraded in an open area in the city of Teresina-Piauí, Brazil, from March to April.

\subsubsection{Degradation in artificial conditions (Ultraviolet radiations)}

The degradation of the pure matrix and composite containing $20 \mathrm{wt} \%$ fibers was also monitored under artificial conditions. The samples were held in the degradation box with fluorescent UV-B, $365 \mathrm{~nm}, 20 \mathrm{~W}$ and $60 \mathrm{~cm}$, for a period of 768 hours. For comparison, the same procedure of the two degradation processes was carried out on samples of bags of commercial oxy-biodegradable plastic.

\section{Results and Discussions}

\subsection{Composites of LDPE - FTIR}

The composites were evaluated by FTIR. The composite absorption spectrum in Figure 2 shows the effect of incorporating the babassu polymer fiber. The mercerization superficial treatment methodology was used in the present study, and sand bath was used for mixing of the materials, to ensure the fibers were well distributed in the polymer matrix.

The presence of fibers in the matrix was observed by the appearance of peaks between $3200-3600 \mathrm{~cm}^{-1}$, which did not exist prior to the formation of the polymer composites, and so pertain only to the fibers. They are assigned to the fiber $\mathrm{OH}$ stretching ${ }^{15,21}$. This peak intensifies with an increase in the amount of fiber added to the composite. The peak at $2934 \mathrm{~cm}^{-1}$, assigned to the fiber $\mathrm{CH}$ stretching, is overlapped by the matrix ${ }^{15}$. The peaks at $1463 \mathrm{~cm}^{-1}, 1421 \mathrm{~cm}^{-1}, 730 \mathrm{~cm}^{-1}$, and $719 \mathrm{~cm}^{-1}$, correspond, respectively, to $\mathrm{CH}_{2}$ (crystalline) deformation, $\mathrm{CH}_{2}$ deformation (amorphous), $\mathrm{CH}_{2}$ rocking vibration (crystalline), and $\mathrm{CH}_{2}$ (amorphous) rocking vibration, which reveal the presence of a paraffinic region of the matrices in the composites ${ }^{23}$.

The appearance of peaks at approximately $1595 \mathrm{~cm}^{-1}$, $1510 \mathrm{~cm}^{-1}$, and $1055-1036 \mathrm{~cm}^{-1}$, which are respectively, stretch aromatic ring $(\mathrm{C}=\mathrm{C})$ lignin, lignin stretch $\mathrm{CO}$, and the $\mathrm{CO}$ stretching and deformation of the cellulose primary alcohol

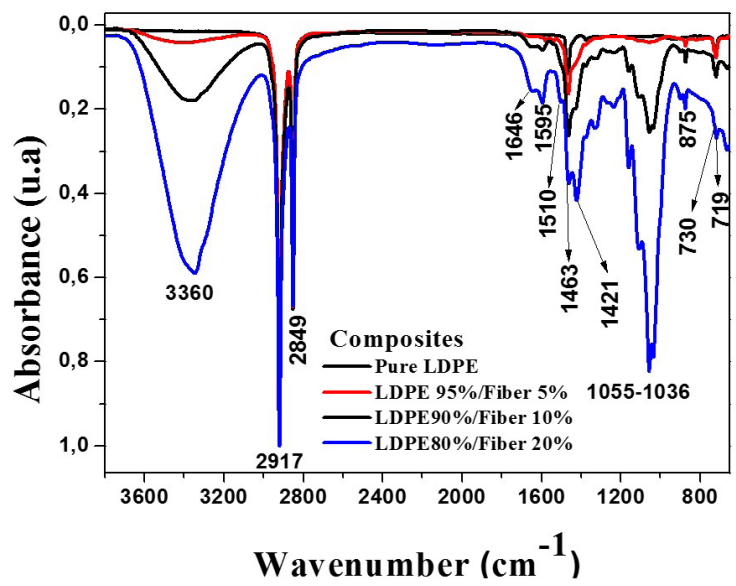

Figure 2. Absorption Spectrum of pure LDPE matrix and babassu fiber composites. 
lignin, showed the presence of the fiber in the composite. The intensity of these peaks also increases as the fiber is added to the matrices ${ }^{14,15,17,21,24-26}$. The fibers incorporation in the matrix contributed to the new composites' properties.

\subsection{Morphology of LDPE composites - SEM}

The morphology of the samples was analyzed by SEM. This technique was used to observe the compatibility of babassu fibers with the LDPE matrix. Figure 3 shows the results for the matrix of pure LDPE and those combined with the treated fiber in different mass proportions.

The pure matrix presents a smooth surface without changes. With the addition of 5\% fiber, the surface change to a rougher appearance, indicating the presence of fibers. The presence of fibers in the matrix is further observed, as more fibers are added, so that the composite containing $20 \%$ by weight fibers appear rougher.

The strong material interaction causes some kind of encapsulation of the fibers in the polymer matrix, which makes it difficult to differentiate them. The mercerization treatment increases the superficial roughness in the fiber and improves mechanical grip. When mercerized fibers are added to a polymer matrix, adhesion occurs through the mechanical anchoring mechanism of the fibers, resulting in a greater physical contact between the two materials ${ }^{27}$. These results agree with the infrared analysis, showing the compatibilizer efficiency used in the method fibers, which
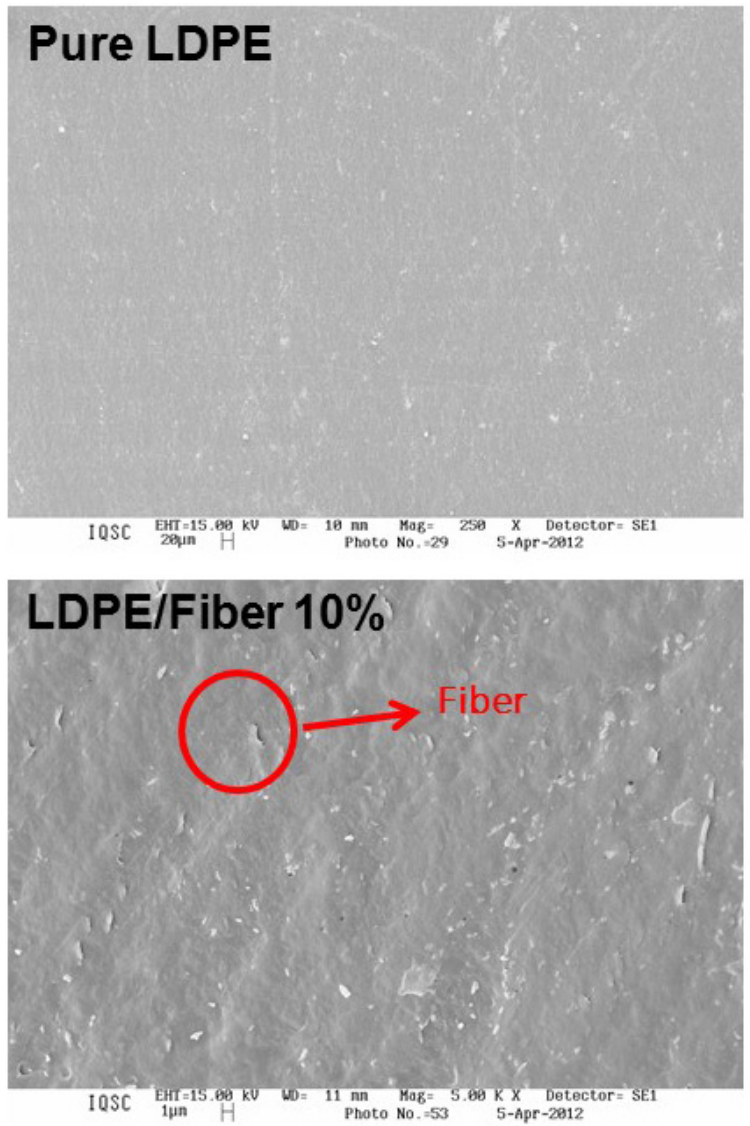

becomes less hydrophilic, and therefore, there is better adhesion among the fiber matrices.

\subsection{Thermal analysis of LDPE composites - TG}

This technique was used to evaluate the materials' weight loss in each range of programmed temperature. Figure 4 shows the results of thermogravimetric analysis (TG\DTG) of the pure LDPE matrix composites with babassu fiber. Due to the absence of water, pure LDPE matrix showed no weight loss between $30-200{ }^{\circ} \mathrm{C}^{12}$ (Figure $4 \mathrm{a}$ and $\mathrm{b}$ ). The degradation starts quickly between $237-500{ }^{\circ} \mathrm{C}$, with a maximum peak at $422{ }^{\circ} \mathrm{C}$. Degradation also occurs in a single stage. With the addition of $5 \%, 10 \%$, and $20 \%$ fibers in the matrix, again there was no observable weight loss related to the loss of fiber moisture between $20-200{ }^{\circ} \mathrm{C}$.

Although in its DTG, well-defined degradation events of the two studied materials occurred, it was not possible to differentiate them in TG, and the degradation occurs ${ }^{15}$ between $250-500{ }^{\circ} \mathrm{C}$.

The results shown in the graph of DTG for the composite, has two temperature degradation ranges which are different from the pure matrix. The first stage is in the temperature range from $220-337^{\circ} \mathrm{C}$ with a maximum at $318^{\circ} \mathrm{C}$, which corresponds to fiber degradation. This can be observed by the increase in the peak at $318{ }^{\circ} \mathrm{C}$, which grows with the increased fiber addition in the LDPE matrix ${ }^{13,15}$. The second stage is in the range from $333-550{ }^{\circ} \mathrm{C}$, with a peak at $412^{\circ} \mathrm{C}$, due to matrix degradation. The degradation of the composites
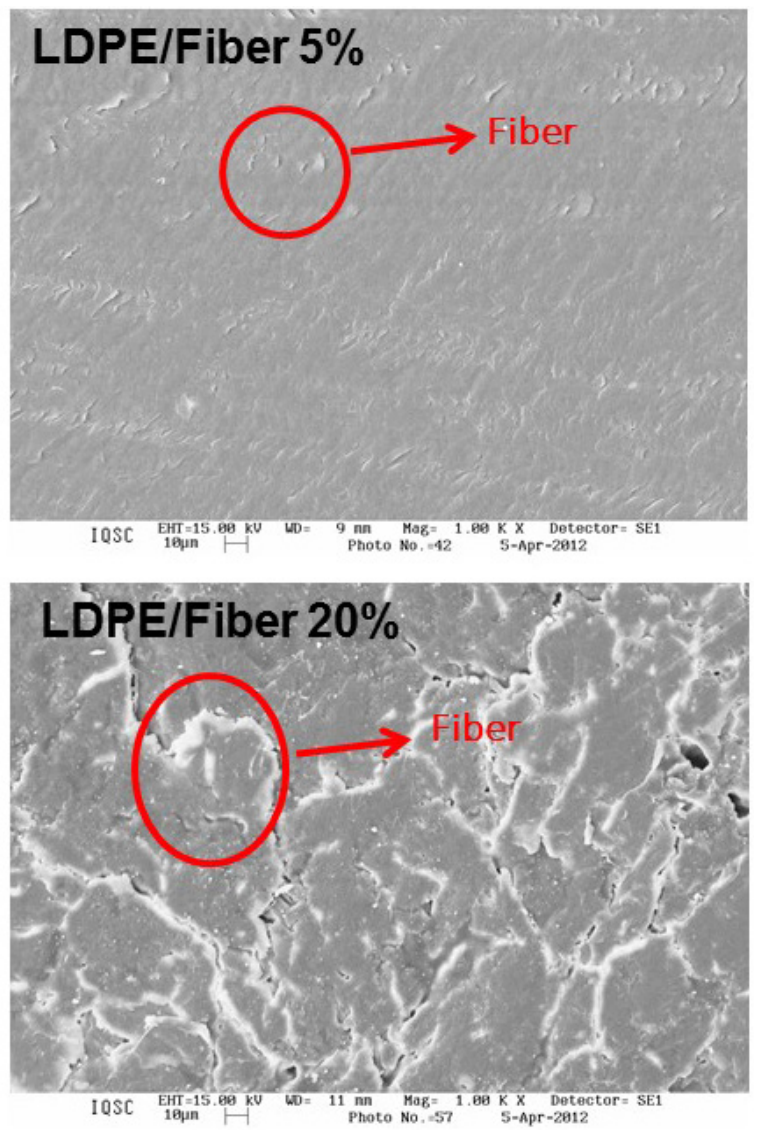

Figure 3. SEM of the pure LDPE matrix and the composites containing babassu fibers. 

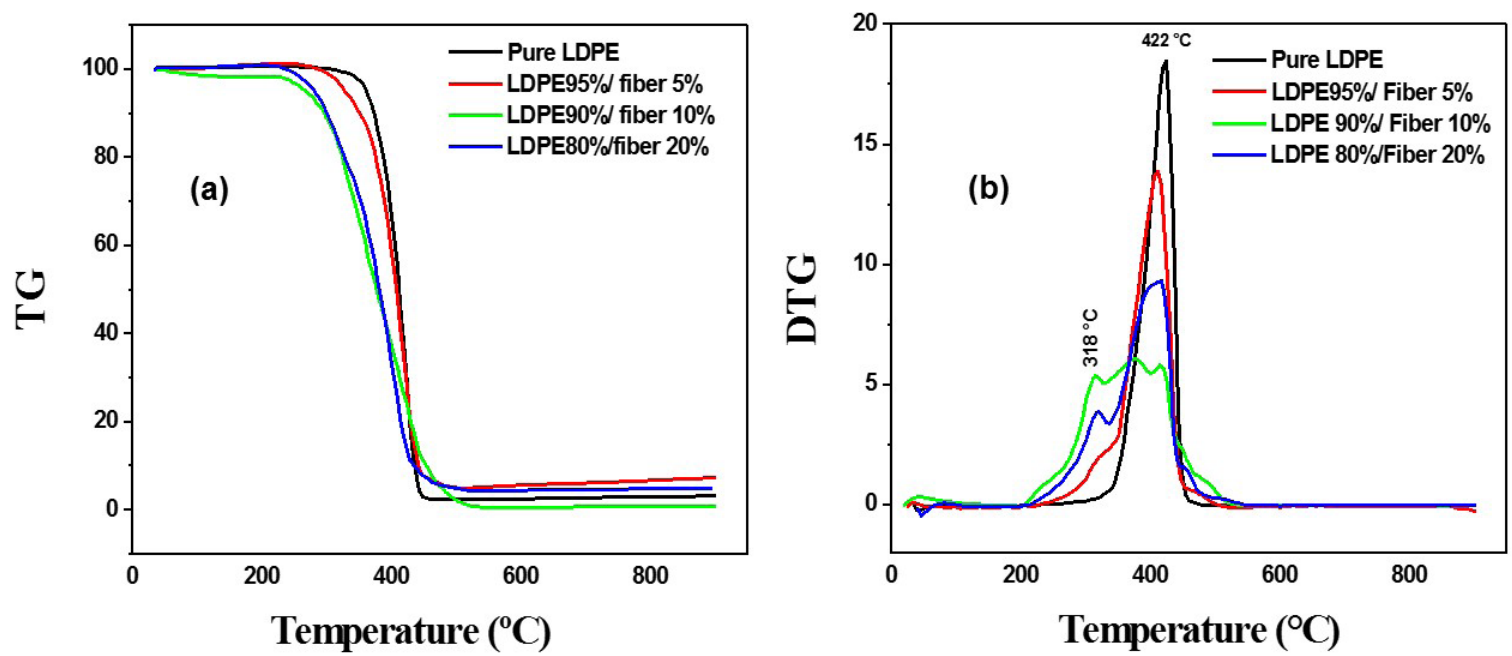

Figure 4. Thermal analysis of the pure matrix of LDPE and composites with babassu fiber (a) TG and (b) DTG.

also takes place to a lesser degree as a result of the materials mixing. The polymeric matrix degrades at a slightly higher temperature than the composites ${ }^{19}$. The materials mixture is less favored for the thermal stability of LDPE composites and fiber.

\subsection{Tensile tests of composites}

Figure 5 shows the results obtained for the composites containing LDPE and babassu fiber treated in different proportions. The Low-density polyethylene is a polymer having specific properties due to its high degree of branching, for example, good toughness, high flexibility, and high impact strength. It can be observed in Table 1 that the results of the tensile tests showed that the pure polymer presents higher tension values $(10.9 \pm 1.99 \mathrm{MPa})$, deformation $(15.7 \pm 0.77 \%)$ and Young's modulus (241.97 $\pm 35.4 \mathrm{MPa})$, since it is the polymer in its pure form. These results are in agreement with the literature ${ }^{28}$.

With the addition of $5 \%, 10 \%$, and $20 \%$ of treated fibers in the pure polymer, it is possible to observe a decrease in the material resistance due to the presence of the fibers. When analyzing the pure polymer and its composite with $5 \%$ added fiber, a decrease of $20.2 \%$ of the tension, $7 \%$ of the deformation, and 3.6\% for Young's modulus was observed. With the addition of $20 \%$ fiber, there is a $44 \%$ drop in tension, $48 \%$ in strain, and $12 \%$ in Young's modulus. These results are in accordance with the literature, as shown by Coutinho et $\mathrm{al}^{29}$. The tensile strength value for LDPE ranges from 6.9-16 MPa, and the Young's modulus ranges from 102-240 MPa. The elastic modulus was the mechanical property that suffered the least degree of variation in all composites.

\subsection{Study of composites degradation}

The polyethylene photochemical degradation results in the formation of the degradation of vinyl and carbonyl groups, which are responsible for the crosslinking process and chain scission, according to De Paoli (2009) ${ }^{28}$. The polymer in the presence of light promotes the free radicals formation with enough energy to break a carbon-carbon or carbon-hydrogen

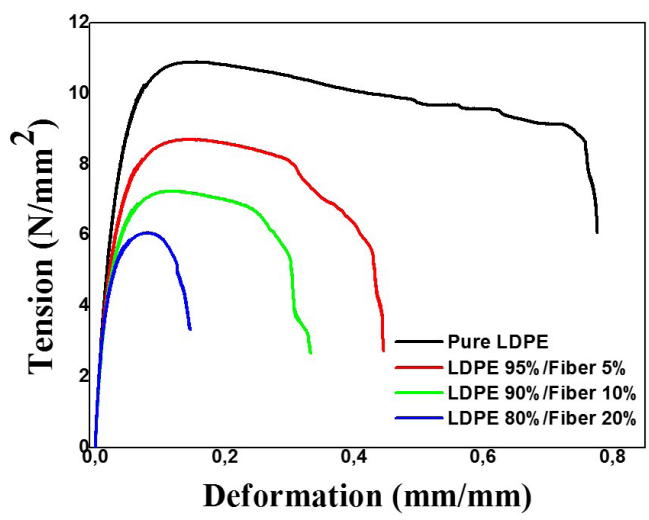

Figure 5. Composites of low-density polyethylene composites containing treated babassu fiber.

Table 1. Results of the tensile test for the composites of LDPE with babassu fiber.

\begin{tabular}{lccc}
\hline \multicolumn{1}{c}{ Sample } & $\begin{array}{c}\text { Tension } \\
(\mathbf{M P a})\end{array}$ & $\begin{array}{c}\text { Deformation } \\
(\mathbf{\%})\end{array}$ & $\begin{array}{c}\text { Young's } \\
\text { modulus } \\
\mathbf{( M P a )}\end{array}$ \\
\hline LDPE 100\% & $10.9 \pm 1.99$ & $15.7 \pm 0.77$ & $241.97 \pm 35.4$ \\
\hline LDPE/Fiber $5 \%$ & $8.7 \pm 0.20$ & $14.6 \pm 0.22$ & $233.28 \pm 8.7$ \\
\hline LDPE/Fiber 10\% & $7.2 \pm 0.75$ & $11.9 \pm 0.36$ & $221.2 \pm 10.6$ \\
\hline LDPE/Fiber 20\% & $6.1 \pm 0.20$ & $8.1 \pm 1.1$ & $211.3 \pm 3.3$ \\
\hline
\end{tabular}

bond. In the absence of oxygen, this promotes the formation of cross-linking reactions, which is the recombination of free radicals. In the presence of oxygen, chain scission with the formation of peroxide radicals occurs. The reaction is extremely fast and controlled by oxygen diffusion in the polymer. These radicals are very unstable peroxides, interacting and removing a hydrogen atom of the same molecule, or a neighboring molecule, to form hydroperoxide groups. In the presence of light, this arrangement is very unstable and chain scission occurs with the formation of carbonyl groups, water, and vinyl groups ${ }^{30}$. The macromolecules become photochemically unstable in the presence of carbonyl groups, because these groups can absorb light in the range of UV wavelength of the 
solar spectrum. Photodegradation is a widely used method to study the degradation of polymers. The photo-oxidative degradation is a material decomposition process in the presence of UV light. UV radiation in the range $290-320 \mathrm{~nm}$ is equivalent to the energy required to dissociate the $\mathrm{C}-\mathrm{C}$ and $\mathrm{C}-\mathrm{H}$ bonds and produce free radicals ${ }^{31}$.

The degradation of pure materials and composites was performed using only the matrix of the composite and pure LDPE in a proportion of $20 \%$ by weight of fiber. The materials were studied by degradation in a natural environment (under sunlight), and an artificial environment (UV-B radiation in fluorescent lamp). For comparison, the same conditions of degradation of oxy-biodegradable plastic shopping bag samples were used. The material's degradation was monitored by FTIR, to observe the formation of new absorption bands resulting from the material's degradation process during different exposures.

\subsubsection{Degradation by solar radiation (LDPE composites)}

All major components of the fibers, cellulose, hemicellulose, and lignin are degraded. The fiber components photodegradation depends on the ability to absorb UV radiation. This concentrates most of the lignin chromophores groups. The UV light absorption initiates the photochemical reaction on the fiber surface leading to the formation of aromatics and other free radicals that cause the degradation of lignin, cellulose, and hemicellulose, by photodissociation of $\mathrm{C}-\mathrm{C}$ bond formations and carbonyl groups. Similar to the fibers photodegradation, the photo-oxidative process of the polyethylene is based on the free radicals, hydroperoxides, and carbonyl groups formation, which are responsible for the UV radiation absorption above $290 \mathrm{~nm}$. The oxygen diffusion in the polymer controls the process of polyolefins degradation. The photodegradation promotes changes in the polymer such as oxidation and chain scission. The reason why the delay degrades polyethylene is the hydrophobic nature of carbon-carbon chains with inert high molecular mass ${ }^{31}$.

The results below show the LDPE composites degradation for a period of 768 hours under solar radiation. For pure LDPE matrix, Figure $6 \mathrm{a}$, two peaks appear, the first at $1720 \mathrm{~cm}^{-1}$ and the second at $1660 \mathrm{~cm}^{-1}$, characteristic of one carbonyl group $(\mathrm{C}=\mathrm{O})$, and $\mathrm{C}=\mathrm{C}$ stretching, respectively. This is probably due to the presence of a chromophore group during the exposure process in the open area rather than the matrix photodegradation process, since the exposure time was very small in natural conditions. The main reasons for the low polyethylene degradability are its hydrophobicity and high molecular weight ${ }^{31,32}$.

With the addition of $20 \%$ fiber matrix of LDPE, shown in Figure 6b, four new peaks appear at $3695 \mathrm{~cm}^{-1}, 3654 \mathrm{~cm}^{-1}$, $3620 \mathrm{~cm}^{-1}$ and $1734 \mathrm{~cm}^{-1}$. The first three peaks should be associated with the hydroxyl formation and the fourth peak, the stretching of the $\mathrm{C}=\mathrm{O}$ ester group. The disappearance of peaks at $1595 \mathrm{~cm}^{-1}$ and $1505 \mathrm{~cm}^{-1}$, related to $\mathrm{C}=\mathrm{C}$ stretching
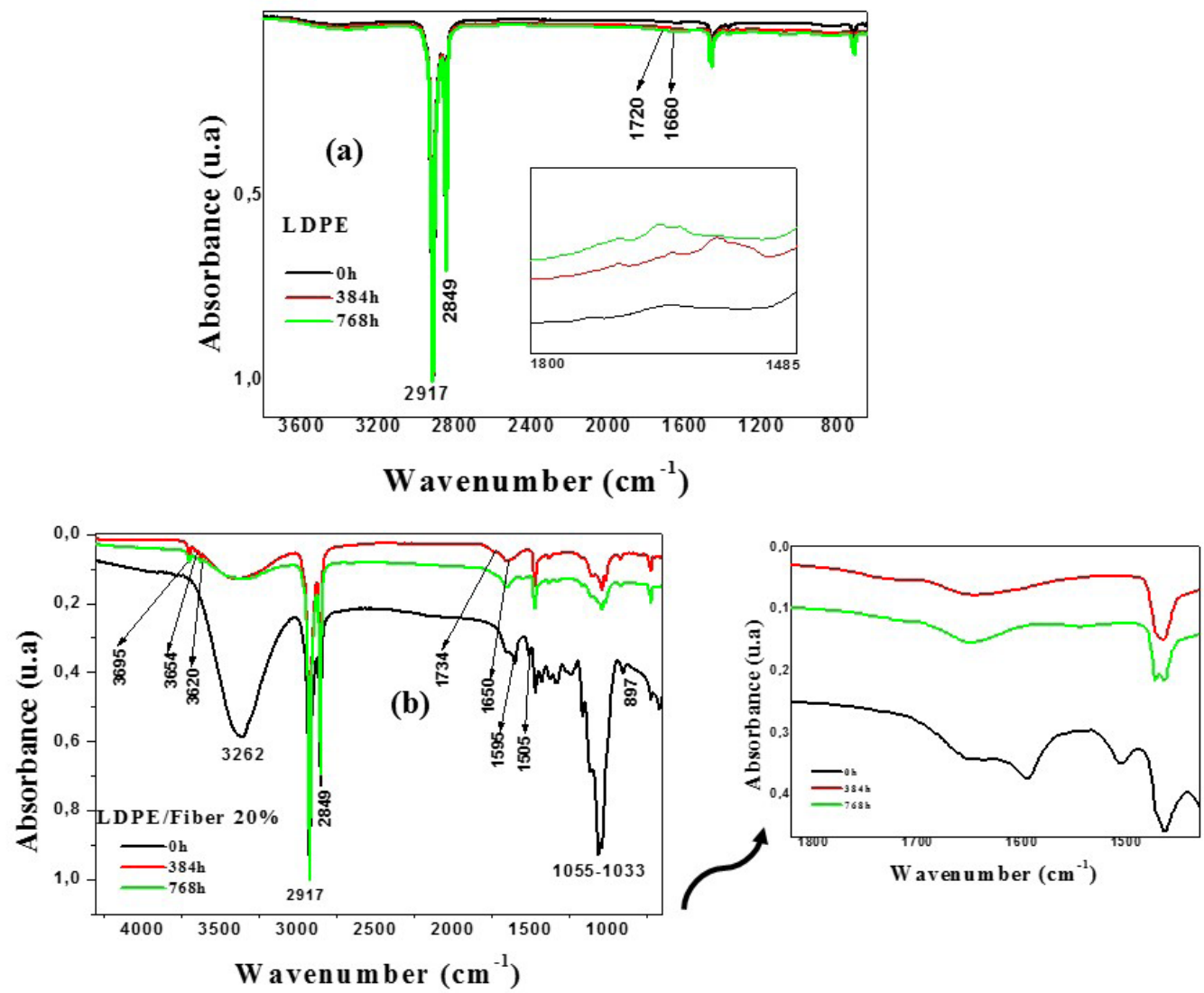

Figure 6. FTIR spectrum of pure LDPE matrix (a) different times of degradation by sunlight and (b) $20 \%$ fiber at different times of degradation by sunlight. 

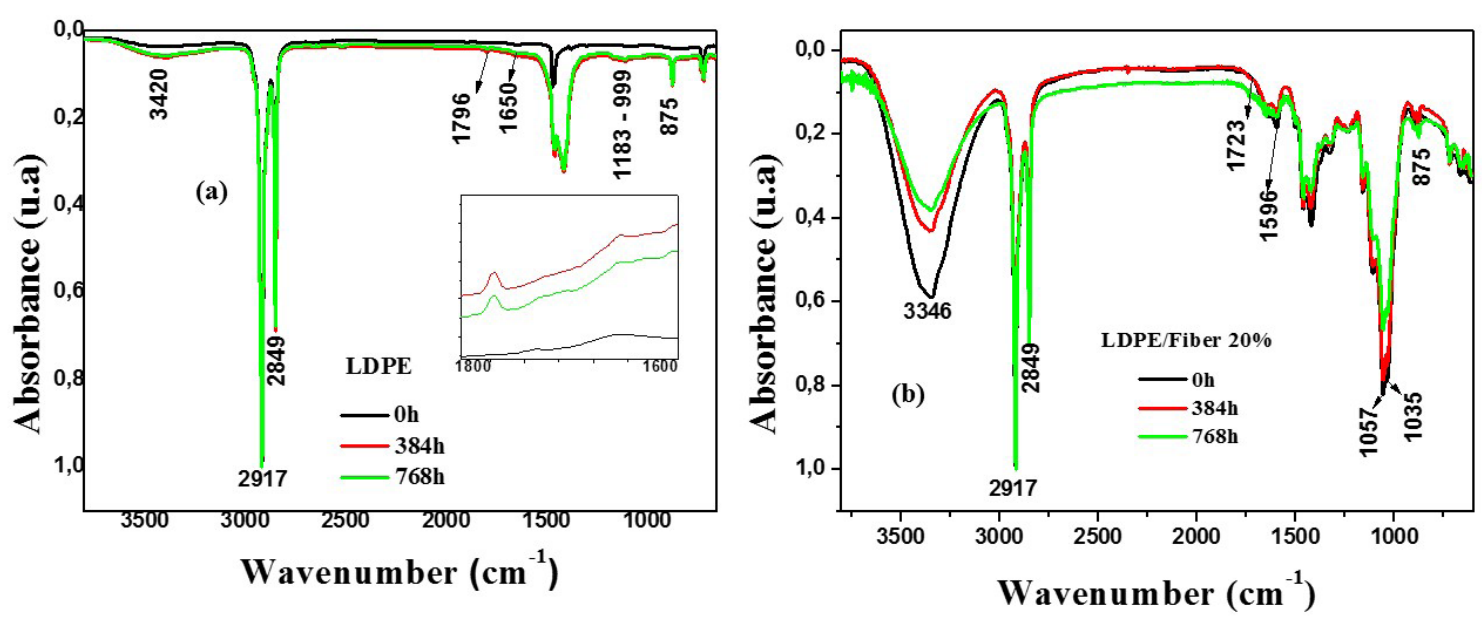

Figure 7. FTIR of pure LDPE matrix (a) different times of degradation in UV-B and (b) $20 \%$ fiber at different times of degradation UV-B.

of the aromatic ring and the $\mathrm{CO}$ group occurs, and again the lignin peak at $1650 \mathrm{~cm}^{-1}$, due to the $\mathrm{C}=\mathrm{C}$ stretch, becomes more defined during exposure.

The peaks correspond to the fiber which experienced a decrease in strength with exposure. These results show that the fiber presence alters the matrices degradation mechanism, favoring an increase in the photodegradation rate.

\subsubsection{Degradation by UV-B radiation (LDPE composites)}

The results of the LDPE composites degradation are shown in Figure 7. It is possible to see in the pure LDPE matrix, Figure $7 \mathrm{a}$, the appearance of a band in the region $3407-3420 \mathrm{~cm}^{-1}$, which did not exist in the polymer, and which increases with exposure time. These bands did not appear during the sun exposure because natural exposure is less intense than the artificial exposure. The presence of these bands is indicative of the hydroxyl formation $(\mathrm{OH}$ free groups or carboxylic acid). It is also possible to see a slight appearance of peaks at $1796 \mathrm{~cm}^{-1}(\mathrm{C}=\mathrm{O}), 1650 \mathrm{~cm}^{-1}(\mathrm{C}=\mathrm{C})$, $1176 \mathrm{~cm}^{-1}(\mathrm{CO})$, and $875 \mathrm{~cm}^{-1}(\mathrm{C}=\mathrm{C}$ deformation) in both matrices. This process is started with the alkyl radical's formation in the polymer due to the chemical bonds rupture in the polymer chain, producing low molecular weight materials. The alkyl radicals formed are unstable and combine with oxygen to form hydroperoxides, which may decompose to form alkoxide radicals. These alkoxides radicals can abstract hydrogen or cause chain scission. Thus, the polymer is degraded to form a mixture of hydroxyl ${ }^{31}$ and carbonyl groups. The other peaks revealed no changes.

Figure $7 \mathrm{~b}$ shows the results for the addition of $20 \%$ fiber in the matrix. In the region between $3600-3200 \mathrm{~cm}^{-1}$, a slight drop in the intensity occurs. The peak at $1723 \mathrm{~cm}^{-1}$ that appears in the composite is associated with carbonyl groups $(\mathrm{C}=\mathrm{O})$. Just as in solar radiation, it occurs in the composites at $1596 \mathrm{~cm}^{-1}$, a decrease of this peak, attributed to lignin. Whereas the emergence of a peak at $875 \mathrm{~cm}^{-1}$ is associated with angular $\mathrm{C}=\mathrm{C}$ deformation, this only appears during artificial exposure. Regarding the other peaks, they exhibit the same degradation process. However, the degradation in an artificial environment was more intense.

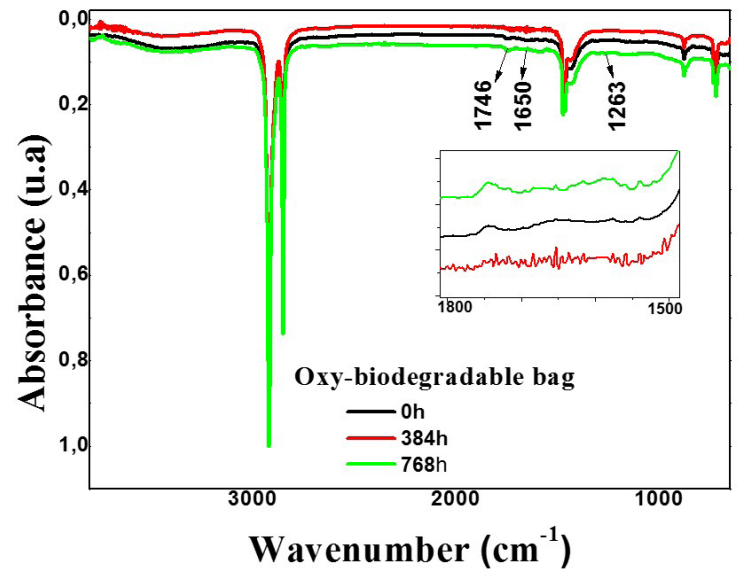

Figure 8. Oxy-biodegradable bag under exposure UV-B.

These results show that with the fiber addition in the polymer matrix, a variation occurs in the degradation mechanism. The addition of a biodegradable material, such as babassu treated fibers, can help the LDPE matrix to increase its degradability.

\subsection{Oxy-biodegradable shopping bag plastic}

\subsubsection{Degradation by UV-B radiation}

For comparison, a piece of commercial oxy-biodegradable plastic bag was also subjected to the same conditions of the composite's degradation. Under UV-B, Figure 8, there was no radiation formation of carbonyl groups during exposure. What happened was a small increase in peak intensity that occurred at $1746 \mathrm{~cm}^{-1}$, and only two peaks showed at $1263 \mathrm{~cm}^{-1}$ and $1650 \mathrm{~cm}^{-1}$. During artificial exposure, the peak at $1263 \mathrm{~cm}^{-1}$, assigned to $\mathrm{CO}_{2}$ stretching, also appears. This shows that oxy-biodegradable plastic releases this group to the atmosphere during the degradation process, contributing to an increase in the greenhouse effect.

When comparing the degradation process of the composites with the oxy-biodegradable plastic bag sample, it is possible to observe that the composites, besides presenting formation 
of carbonyl groups, with a peak in $1723 \mathrm{~cm}^{-1}$, which did not previously exist, but now appears during the exposure (and which is characteristic of the degradation process), the degradation happens without release of $\mathrm{CO}_{2}$ groups in the atmosphere. These results show an improvement in the photodegradation potential of the polyethylene matrix with the addition of babassu palm fiber.

\section{Conclusions}

The proposed chemical treatments allowed the production of high-quality fibers with a high distribution and adhesion level to the polymer matrix, promoting composites formation. The study of their properties using SEM and FTIR, revealed good interfacial compatibility between the materials. TG analyses showed that the fiber-matrix incorporation allows greater stability of the thermal breakdown process, and a minor weight loss of the composites, respectively. Unlike the composites, during the degradation process, the oxy-biodegradable plastic bag releases catalyst residues and $\mathrm{CO}_{2}$ into nature. With these results, the babassu fiber showed promise in the formation of composite materials in an LDPE matrix.

\section{Acknowledgments}

The authors would like to thank CAPES, PLASTNOR for the LDPE samples, the Interdisciplinary Laboratory for Advanced Materials -LIMAV, Federal University of Piauí - UFPI and the Research Group in the Materials and Metrology Institute Federal do Piauí - IFPI for analyses.

\section{References}

1. Kalia S, Kaith BS. Cellulose fibers: bio-and nano-polymer composites. Green chemistry and technology. USA: Springer; 2011.

2. Barreto ACH, Rosa DS, Fechine PBA, Mazzetto SE. Properties of sisal fibers treated by alkali solution and their application into cardanol-based biocomposites. Compos, Part A Appl Sci Manuf. 2011;4:492-500. http://dx.doi.org/10.1016/j. compositesa.2011.01.008.

3. Silva R, Haraguchi SK, Muniz EC, Rubira AF. Aplicação de fibras lignocelulósicas na química de polímeros em compósitos. Quim Nova. 2011;32:661-71. http://dx.doi.org/10.1590/S010040422009000300010.

4. Qin C, Soykeabkaew N, Xiuyuan N, Peijs T. The effect of fiber volume fraction and mercerization on the properties of all-cellulose composites. Carbohydr Polym. 2008;71:458-67. http://dx.doi.org/10.1016/j.carbpol.2007.06.019.

5. Wang X, Cui Y, Xu Q, Xie B, Li W. Effects of alkali and silane treatment on the mechanical properties of jute-fiber-reinforced recycled polypropylene composites. J Vinyl Addit Techn. 2010;16:183-8. http://dx.doi.org/10.1002/vnl.20230.

6. Zaman HU, Khan MA, Khan RA. A comparative study on the mechanical and degradation properties of plant fiber reinforced polyethylene composites. Polym Compos. 2011;32:1552-60. http://dx.doi.org/10.1002/pc.21168.

7. Aji IS, Sapuan SM, Zainudin ES, Abdan K. Kenaf fiber as reinforcement for polymeric composites: a review. International Journal of Mechanical and Materials Engineering [serial on the Internet]. 2009 [cited 2019 Jul 24];4:239-48. Retrieved from https://www.researchgate.net/publication/242523500

8. Kalia S, Kaith BS, Kaur I. Preteatments of natural fibers and their application as reinforcing material in polymer composites
- a review. Polym Eng Sci. 2009;49:1253-72. http://dx.doi. org/10.1002/pen.21328.

9. Finkler M, Scapini P, Freire E, Zattera AJ, Zeni M. Compósitos de HDPE com resíduos de fibras têxteis. Parte I - caracterização mecânica. Polímeros. 2005;15:171-5. http://dx.doi.org/10.1590/ S0104-14282005000300006.

10. Palova SB, Lawrence LV, Ricardo B, Daniela B, Valdir S, Antônio $\mathrm{R}$, et al. Estudo das propriedades mecânicas de um composto de PVC modificado com fibras de bananeira. Polímeros. 2007;17:14. http://dx.doi.org/10.1590/S0104-14282007000100004.

11. Kocsis JK, Mahmood H, Pegoretti A. Recent advances in fiber/matrixinterphase engineering for polymer composites. Prog Mater Sci. 2015;73:1-43. http://dx.doi.org/10.1016/j. pmatsci.2015.02.003.

12. Huzaifah MRM, Sapuan SM, Leman Z, Ishak MR. Comparative study on chemical composition, physical,tensile, and thermal properties of sugar palm fiber (Arenga pinnata) obtained from different geographical locations. BioResources, 2017;12:936682. http://dx.doi.org/10.15376/biores.12.4.9366-9382.

13. Huzaifah MRM, Sapuan SM, Leman Z, Ishak MR, Maleque MA. A review of sugar palm (Arenga pinnata): application, fiber characterisation and composites. Multidiscipline Modeling in Materials and Structures, 2017;13:678-8. http://dx.doi. org/10.1108/MMMS-12-2016-0064.

14. Ilyas RA, Sapuan SM, Ishak MR. Isolation and characterization of nanocrystalline cellulose from sugar palm fibers (Arenga Pinnata). Carbohydr Polym. 2018;181:1038-51. http://dx.doi. org/10.1016/j.carbpol.2017.11.045.

15. Ilyas RA, Sapuan SM, Ishak MR, Zainidim ES. Effect of delignification on the physical, thermal,chemical, and structural properties of sugar palm fiber. BioResources. 2017;12:8734-54. http://dx.doi.org/10.15376/biores.12.4.8734-8754.

16. EL-Shekeil YA, Sapuan SM, Khalina A, Zainudin ES, AL-Shuja'a OM. Effect of alkali treatment on mechanical and thermal properties of Kenaf fiber-reinforced thermoplastic polyurethane composite. J Therm Anal Calorim. 2012;109:1035-444. http:// dx.doi.org/10.1007/s10973-012-2258.

17. Ashori A, Ornelas M, Sheshmani S, Cordeiro N. Influence of mild alkaline treatment on the cellulosic surfaces active sites. Carbohydr Polym. 2012;88:1293-8. http://dx.doi.org/10.1016/j. carbpol.2012.02.008.

18. Santos RS, Souza AA, Paoli M, Souza CML. Cardanolformaldehyde thermoset composites reinforced with buriti fibers: preparation and characterization. Compos, Part A Appl Sci Manuf. 2010;41:1123-9. http://dx.doi.org/10.1016/j. compositesa.2010.04.010.

19. Kim JT, Netravali AN. Mercerization of sisal fibers: effect of tension on mechanical properties of sisal fiber and fiber-reinforced composites. Compos, Part AAppl Sci Manuf. 2012;41:1245-52. http://dx.doi.org/10.1016/j.compositesa.2010.05.007.

20. Bachtiar D, Sapuan SM, Hamdan MM. The effect of alkaline treatment on tensile properties of sugar palm fiber reinforced epoxy composites. Mater Des. 2008;29:1285-90. http://dx.doi. org/10.1016/j.matdes.2007.09.006.

21. Ilyas RA, Sapuan SM, Ibrahim R, Abral H, Ishak MR, Zainudin ES, et al. Sugar palm (Arenga pinnata (Wurmb.) Merr) cellulosic fibre hierarchy: a comprehensive approach from macro to nano scale. J Mater Res Technol, 2019;8:2753-66. http://dx.doi. org/10.1016/j.jmrt.2019.04.011.

22. Bonneli CMC, Elzubair A, Suarez JCM, Mano EB. Comportamento térmico, mecânico e morfológico de compósitos de polietileno de alta densidade reciclado com fibra de piaçava. Polímeros. 2005;15:256-60. http://dx.doi.org/10.1590/S010414282005000400009

23. Nadirah WOW, Jawaid M, Al Masri AA, Khalil HPSA, Suhaily SS, Mohamed AR. Cell wall morphology, chemical and thermal analysis of cultivated pineapple leaf fibers for industrial 
applications. J Polym Environ. 2012;20:404-11. http://dx.doi. org/10.1007/s10924-011-0380-7.

24. Pandey JK, Kim CS, Chu WS, Choi WY, Ahn SH, Lee CS. Preparation and structural evaluation of nano reinforced composites from cellulose whiskers of grass and biodegradable polymer matrix. J Compos Mater. 2012;46:655-63. http://dx.doi. org/10.1177/0021998312438174.

25. Satyanarayana KG, Guimarães JL, Wypych F. Studies on lignocellulosic fibers of Brazil, Part I: Source, production, morphology, properties and applications. Compos, Part AAppl Sci Manuf. 2007;38:1694-709. http://dx.doi.org/10.1016/j. compositesa.2007.02.006.

26. Matuana LM, Jin S, Stark NM. Ultraviolet weathering of HDPE/wood-flour composites coextruded with a clear HDPE cap layer. Polym Degrad Stabil. 2011;96:97-106. http://dx.doi. org/10.1016/j.polymdegradstab.2010.10.003.

27. Albinante SR, Pacheco EBAV, Visconte LLY. Revisão dos tratamentos químicos da fibra natural para mistura com poliolefinas. Quim Nova. 2013;36:114-22. http://dx.doi. org/10.1590/S0100-40422013000100021.

28. De Paoli MA. Degradação e estabilização de polímeros. São Paulo: Artliber Ed.; 2009.

29. Coutinho FMB, Mello IL, Maria LCS. Polietileno: principais tipos, propriedades e aplicações. Polímeros. 2003;13:1-13. http://dx.doi.org/10.1590/S0104-14282003000100005.

30. Ojeda TFM. Biodegradabilidade de materiais poliméricos [Tese]. Porto Alegre: Faculdade de Agronomia, Universidade Federal do Rio Grande do Sul; 2008.

31. Roy PK, Surekha P, Rajagopal C. Surface oxidation of lowdensity polyethylene films to improve their susceptibility toward environmental degradation. J Appl Polym Sci. 2011;122:276573. http://dx.doi.org/10.1002/app.34097.

32. Kumanayaka TO, Parthasarathy R, Jollands M. Accelerating effect of montmorillonite on oxidative degradation of polyethylene nanocomposites. Polym Degrad Stabil. 2010;95:672-6. http:// dx.doi.org/10.1016/j.polymdegradstab.2009.11.036. 